SANDIA REPORT

SAND97-1149 • UC-600

Unlimited Release

Printed May 1997

\title{
Evaluation of an Open-Path Fourier- Transform Infrared Spectrometer for Monitoring Vehicle Emissions Over a Suburban Roadway Intersection
}

Wayne Einfeld

Prepared by

Sandia National Laboratories

Albuquerque, New Mexico 87185 and Livernate California 94550

Sandia is a multiprogram laboratory oberato. by Sondip

Corporation, a Lockheed Martin Company, to the Unit is St to

Department of Energy under Contract DE-ACO4-94AL85000 Whis

Approved for public release, distribution is unlinited.
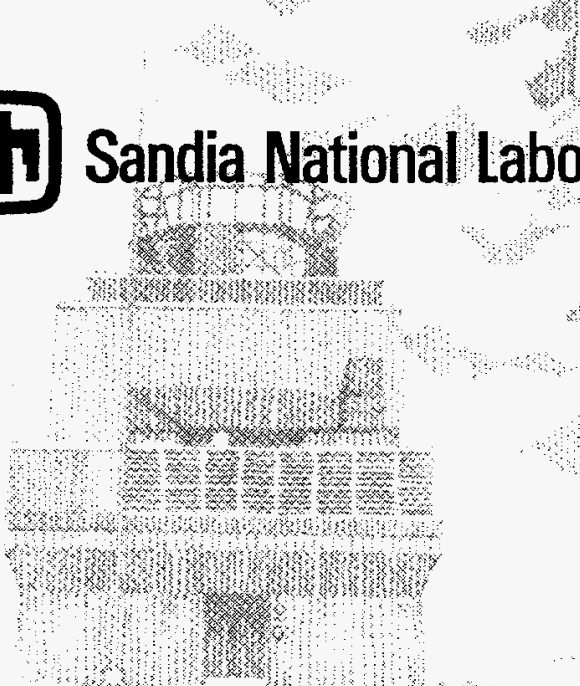

,

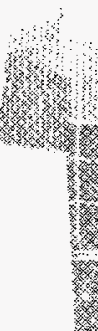

Whombmom

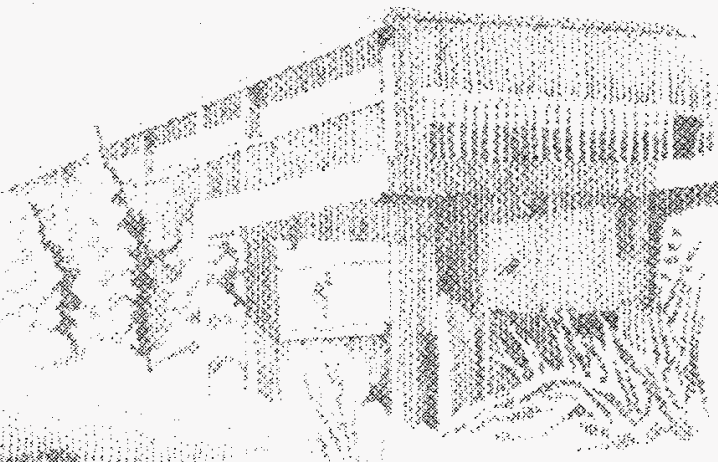


Issued by Sandia National Laboratories, operated for the United States Department of Energy by Sandia Corporation.

NOTICE: This report was prepared as an account of work sponsored by an agency of the United States Government. Neither the United States Government nor any agency thereof, nor any of their employees, nor any of their contractors, subcontractors, or their employees, makes any warranty, express or implied, or assumes any legal liability or responsibility for the accuracy, completeness, or usefulness of any information, apparatus, product, or process disclosed, or represents that its use would not infringe privately owned rights. Reference herein to any specific commercial product, process, or service by trade name, trademark, manufacturer, or otherwise, does not necessarily constitute or imply its endorsement, recommendation, or favoring by the United States Government, any agency thereof, or any of their contractors or subcontractors. The views and opinions expressed herein do not necessarily state or reflect those of the United States Government, any agency thereof, or any of their contractors.

Printed in the United States of America. This report has been reproduced directly from the best available copy.

Available to DOE and DOE contractors from

Office of Scientific and Technical Information

P.O. Box 62

Oak Ridge, TN 37831

Prices available from (615) 576-8401, FTS 626-8401

Available to the public from

National Technical Information Service

U.S. Department of Commerce

5285 Port Royal Rd

Springfield, VA 22161

NTIS price codes

Printed copy: A0

Microfiche copy: A01 


\section{DISCLAIMER}

This report was prepared as an account of work sponsored by an agency of the United States Government. Neither the United States Government nor any agency thereof, nor any of their employees, make any warranty, express or implied, or assumes any legal liability or responsibility for the accuracy, completeness, or usefulness of any information, apparatus, product, or process disclosed, or represents that its use would not infringe privately owned rights. Reference herein to any specific commercial product, process, or service by trade name, trademark, manufacturer, or otherwise does not necessarily constitute or imply its endorsement, recommendation, or favoring by the United States Government or any agency thereof. The views and opinions of authors expressed herein do not necessarily state or reflect those of the United States Government or any agency thereof. 


\section{DISCLAMMER}

Portions of this document may be illegible in electronic image products. Images are produced from the best available original document. 
SAND97-1149

Distribution

Unlimited Release

Printed May 1997

Category UC-600

\title{
Evaluation of an Open-Path Fourier-Transform Infrared Spectrometer for Monitoring Vehicle Emissions Over a Suburban Roadway Intersection
}

\author{
Wayne Einfeld \\ Environmental Characterization and Monitoring Department \\ Sandia National Laboratories \\ PO BOX 5800 \\ Albuquerque, NM 87185-0755
}

\begin{abstract}
The ability of an open-path, fourier-transform infrared spectrometer to detect vehicle exhaust emissions approximately 3 meters above the roadway surface at a busy Albuquerque suburban intersection was evaluated in this study. Multiple measurements of carbon monoxide and carbon dioxide were carried out over pathlengths up to 100 meters during the morning commute period on multiple days in the summer of 1993. The carbon monoxide to fuel carbon ratio was computed from all spectral data in order to derive a vehicle fleet average ratio. The data were determined to be normally distributed with an overall carbon monoxide-fuel carbon ratio of 0.15 . The $95 \%$ confidence interval about the mean was \pm 0.009 . Day-to-day variation of the mean ratio was determined to be on the order of $3 \%$. The results indicate that anticipated reductions in carbon monoxide emissions following the implementation of a winter-season oxygenated fuel program could be reliably detected with an open-path fourier transform spectrometer. The periodic use of such an instrument may offer a cost-effective means of generating a citywide carbon monoxide emission budget for vehicular sources.
\end{abstract}


INTRODUCTION -

Open-Path FT-IR Spectroscopy 1

Internal Engine Combustion Emissions-

Oxygenated Fuels

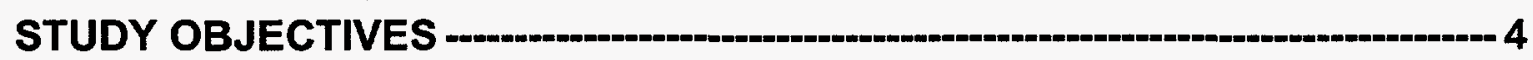

EXPERIMENTAL METHODS-ב-_- 5

FT-IR Description -._- 5

Site Description - 6

Data Processing ___ 9

RESULTS - 11

Measurement Summary-____-11

Spectral Features - 11

Temporal Considerations -

CO-Fuel Carbon Ratios _ _

Statistical Analyses -_______-16

Descriptive Statistics--

Tests for Normal Distribution --

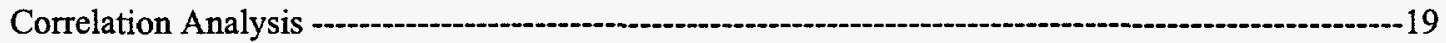

T-Test for Independent Observations ------

Method Sensitivity to Detect CO Emission Reduction --

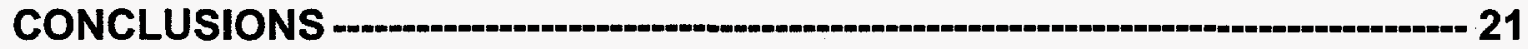

REFERENCES-1- 23 


\section{List of Tables}

Table 1 Engine Combustion Product Concentrations as a Function of Air-Fuel Ratio - 3

Table 2 Typical Spectrum Collection and Processing Parameters -_- 6

Table 3 IR Absorption Bands Used in Quantitative Analysis--_-_-_-11

Table 4 Test Measurement Summary -

Table 5 Summary Statistics for CO2, $\mathrm{CO}$ and the CO-Fuel Carbon Ratio-_-16

Table 6 Summary CO-fuel carbon Ratio Statistics for September 15 and 23 -

\section{List of Figures}

Figure 1 Estimated exhaust $\mathrm{CO}$-Fuel Carbon ratio as a function of engine air-fuel ratio -_-___- 3

Figure 2 The telescope/interferometer/detector portion of the FT-IR spectrometer. -___-_-_-5

Figure 3 The tripod-mounted source associated with the FT-IR system. - 6

Figure 4 A view of the San Mateo - Montgomery intersection.

Figure 5 A diagram of the San Mateo-Montgomery intersection. -

Figure 6 An atmospheric infrared emission spectrum collected under test conditions with the IR source turned off.

Figure 7 A traffic-free ambient air spectrum (upper) and a high-traffic spectrum (lower) showing spectral features in the $C O\left(2225-2050 \mathrm{~cm}^{-1}\right)$ absorption band.

Figure 8 A typical background-corrected test spectrum during a high-traffic period showing $\mathrm{CO}$ absorption features in the $2225-2050 \mathrm{~cm}^{-1}$ band. - 12

Figure 9 A typical background-corrected test spectrum during a high-traffic period showing $\mathrm{CO}_{2}$ absorption features in the $721-718 \mathrm{~cm}^{-1}$ band.

Figure 10 Background-corrected $\mathrm{CO}_{2}$ concentrations for Sept. 23, AM.

Figure 11 Background-corrected CO concentrations for Sept. 23, AM. -._-14

Figure 12 A plot of the CO-fuel carbon ratio for all measurements on Sep. 23 AM.

Figure $13 \mathrm{~A}$ histogram of all $\mathrm{CO}_{2}$ measurements made during periods of high traffic activity.-----17

Figure 14 A histogram of all $\mathrm{CO}$ measurements made during periods of high traffic activity. - -17

Figure 15 A histogram for all computed values of the $\mathrm{CO}$-fuel carbon ratio.--__

Figure 16 A normal probability plot for the CO-fuel carbon Ratio. - - 19

Figure 17 A correlation plot of all measured $\mathrm{CO}$ data vs. $\mathrm{CO}+\mathrm{CO}_{2}$ 


\section{Introduction}

\section{Open-Path FT-IR Spectroscopy}

Open-path fourier transform infrared (FT-IR) spectroscopy is an extension of conventional FT-IR spectroscopy that enables quantitative measurements of atmospheric gaseous species over long pathlengths in the open atmosphere using spectroscopic principles ${ }^{1,2}$. The hardware used for this type of measurement is essentially the same as that used in the laboratory over the past several decades with the exception that an extended, open-path beam configuration is used. This open-path configuration offers some interesting measurement opportunities for air samples that are not easily measured in the laboratory. Remote sensing measurements, including open-path FT-IR systems, provide truly in situ measurements for numerous pollutants of interest. The gas species being measured are not extracted from the air parcel in which they normally exist. Sample handling complications and losses are thus eliminated yielding an accurate and representative measurement result. Furthermore, with FT-IR, multiple species can be determined from the same measurement, thus eliminating the problems associated with electronic noise and drift from multiple instruments.

In this study, the open-path FT-IR system's applicability to remote sensing of vehicular emissions was evaluated. Vehicular emissions have historically been measured via direct sampling probes in vehicle exhaust pipes or by point sampling instruments in the vicinity of vehicular sources. Recently, techniques have been developed for remote sensing of the exhaust products from single on-road vehicles ${ }^{3,4}$. Data collected with these instruments have been used to assess individual vehicle performance in many cities worldwide ${ }^{5}$. The technique is labor intensive however, since the make and year of each on-road vehicle measured must subsequently be extracted from state motor vehicle registration data bases. The use of an extended beam path over a busy urban intersection offers the possibility of collecting an average concentration of the various exhaust pollutants of interest such that an overall vehicle fleet average composition can be developed for an urban locale. Information such as this is useful in the assessment of the effectiveness of air pollution control measures. For example, the implementation of an oxygenated fuel program to reduce vehicular carbon monoxide ( $\mathrm{CO}$ ) emissions might be monitored by such a remote sensing system to gauge the overall effectiveness of the fuel additive program. The US Environmental Protection Agency has published a number of studies that suggest an overall $17 \%$ reduction in $\mathrm{CO}$ emissions from vehicular sources following the implementation of oxygenated fuel programs during the winter season; however, such estimates have considerable uncertainty and are often difficult to develop since they rely on extensive and costly single vehicle testing ${ }^{6}$. The development of an overall average $\mathrm{CO}$ emission level, based on measurement with a remote sensing system such as an open-path FT-IR spectrometer at a busy urban intersection, enables $\mathrm{CO}$ emissions from many vehicles to be measured in an aggregate form without costly testing of numerous individual vehicles. 
A key element of this study involves use of a tracer species in order to relate the $\mathrm{CO}$ measurements directly to fuel mass consumption. Carbon monoxide concentrations in the air surrounding a busy urban intersection vary considerably and will be strongly influenced by the traffic volume through the intersection at any particular point in time, the type of vehicles passing through the intersection, and the prevailing meteorological conditions such as atmospheric mixing height, wind speed, and direction. The amount of information to be derived from $\mathrm{CO}$ measurements can be taken a step further however if a parallel measurement of carbon dioxide $\left(\mathrm{CO}_{2}\right)$ is made as well, since the combination of $\mathrm{CO}$ and $\mathrm{CO}_{2}$ can be used as a tracer of the amount of fuel consumed in an internal combustion engine.

\section{Internal Engine Combustion Emissions}

Ideally, complete oxidation of a hydrocarbon fuel in an internal combustion engine yields only two products, namely, $\mathrm{CO}_{2}$ and water. However, under actual combustion conditions, many products of incomplete combustion are formed ${ }^{7}$. For example, some fuel passes through the engine unburned and exits as hydrocarbon vapor. Some of the fuel is incompletely oxidized and is emitted as $\mathrm{CO}$. Oxides of nitrogen $\left(\mathrm{NO}_{\mathrm{x}}\right)$ are also formed as atmospheric nitrogen combines with oxygen atoms in the high temperature environment inside the combustion chamber. The air-fuel ratio, in large part, determines which products are favored during the combustion process ${ }^{8}$. The air-fuel ratio is defined as the mass ratio of air and fuel mixed and burned in the combustion chamber. High airfuel ratios (fuel-lean conditions) tend to favor the formation of nitrogen oxides as a result of higher combustion temperatures; whereas, low air-fuel ratios (fuel-rich conditions) tend to favor the formation of $\mathrm{CO}$ as well as higher levels of unburned or partially burned hydrocarbons in the exhaust.

Expected concentrations of exhaust species from an internal combustion engine at several air-fuel ratios are given in Table 1. The stoichiometric point is defined as the specific mass ratio of air and fuel required to obtain complete fuel oxidation with no excess oxygen in the combustion products. For a typical hydrocarbon fuel, the stoichiometric value of the air-fuel ratio for an internal combustion engine is about 14.6. The air-fuel ratio of vehicles typically drops below the stoichiometric point (into fuel-rich conditions) during intervals of cold engine operation when the engine and fuel temperature is low and fuel volatility is reduced. In cold conditions, only some fraction of the fuel is fully volatilized and available is for combustion. The non-volatilized fuel is emitted either unburned or partially burned. Consequently, carbon monoxide emissions are highest during these periods of cold-engine operation. 
Table 1 Engine Combustion Product Concentrations as a Function of Air-Fuel Ratio (adapted from Ref. 7)

\begin{tabular}{|c|c|c|c|c|}
\hline $\begin{array}{c}\text { Air-Fuel } \\
\text { Ratio }\end{array}$ & $\begin{array}{c}\mathbf{C O}_{2} \\
(\text { mole } \%)\end{array}$ & $\begin{array}{c}\text { CO } \\
(\text { mole } \%)\end{array}$ & $\begin{array}{c}\text { NOx } \\
(\mathbf{p p m})\end{array}$ & $\begin{array}{c}\text { Hydrocarbons } \\
(\mathbf{p p m})\end{array}$ \\
\hline 11 & 8.2 & 9.5 & 100 & 600 \\
\hline 12 & 10.0 & 6.7 & 200 & 475 \\
\hline 13 & 11.5 & 4.7 & 700 & 425 \\
\hline 14 & 13.5 & 2.0 & 800 & 350 \\
\hline 15 & 14.5 & 0 & 2,100 & 275 \\
\hline 16 & 13.5 & 0 & 2,100 & 250 \\
\hline 17 & 12.7 & 0 & 1,500 & 200 \\
\hline
\end{tabular}

Since carbon is conserved in the combustion reaction, the total carbon in the exhaust products can be used as a tracer of fuel carbon. Examination of the data in Table 1 reveals that the $\mathrm{CO}$ and $\mathrm{CO}_{2}$ exhaust products comprise nearly all the fuel carbon exhaust products. The typical hydrocarbon content of the exhaust is about three orders of magnitude lower than the $\mathrm{CO}$ and $\mathrm{CO}_{2}$ concentrations, thus the combination of $\mathrm{CO}$ and $\mathrm{CO}_{2}$ can be used as an tracer or indicator of fuel carbon. The ratio of $\mathrm{CO}$ to total fuel carbon (as represented by $\mathrm{CO}_{2}+\mathrm{CO}$ ) is essentially an emission factor for $\mathrm{CO}$ from an internal combustion engine and can be used as an indirect measure of combustion efficiency. The CO-fuel carbon ratio will vary with the air-fuel ratio of a particular engine as shown in Figure 1. At stoichiometric conditions the ratio is about 0.05 . The ratio climbs to about 0.14 at an air-fuel ratio of 14 , and continues climbing as the air-fuel mixture becomes more fuel rich. This observation is of particular importance in light of the data produced in this study and will be further discussed in a later section of this report.

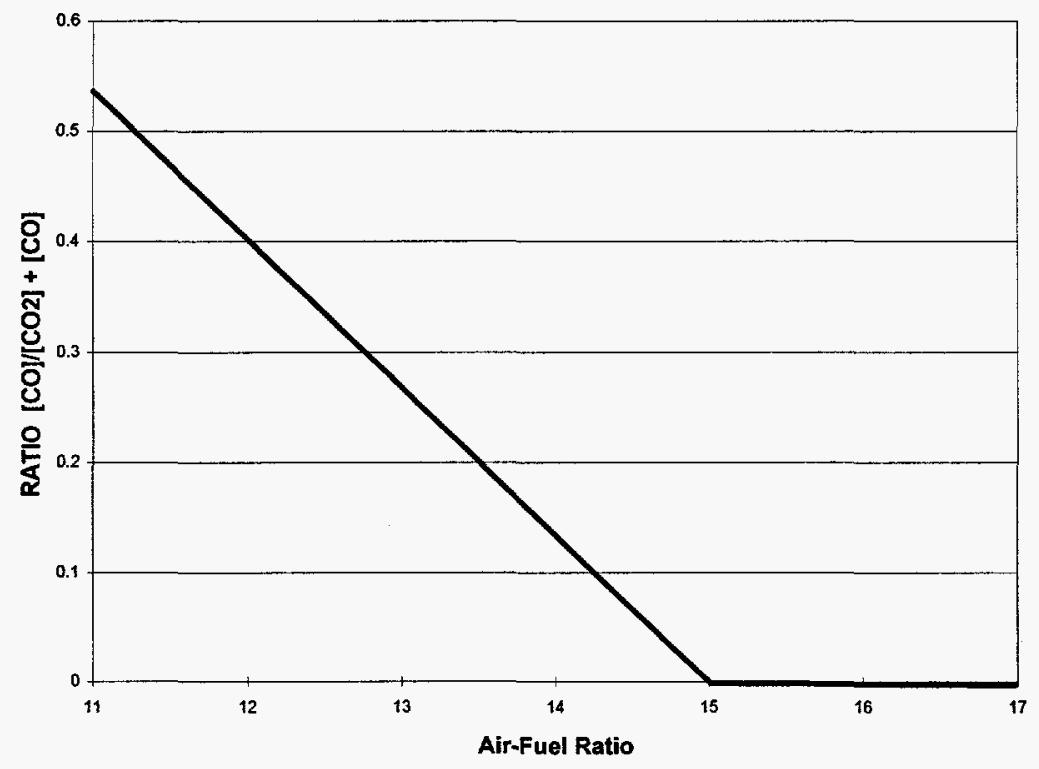

Figure 1 Estimated exhaust CO-Fuel Carbon ratio as a function of engine air-fuel ratio (adapted from Seinfeld, 1986). 


\section{Oxygenated Fuels}

One proposed application of open-path FT-IR spectroscopy under evaluation in this study is its use as a diagnostic tool for assessment the overall reduction in $\mathrm{CO}$ emissions from vehicular sources following the implementation of a winter season oxygenated fuel program. Oxygenated fuels are gasoline blends that include either ethanol or methyl tertiary butyl ether (MTBE) as an additional source of oxygen in the fuel to enhance combustion efficiency. Usually, the oxygen content of the fuel is increased to $2.7 \%$ with the addition of these oxygenated hydrocarbons. Recent EPA studies have indicated that an overall average reduction of $17 \%$ in $\mathrm{CO}$ emissions from vehicular sources is derived from the use of oxygenated fuels. The 1990 amendments to the Clean Air Act requires that oxygenated fuels be used in areas that are designated non-attainment for the ambient air $\mathrm{CO}$ standard ${ }^{9}$, and at the present time, oxygenated fuel programs are implemented in about 32 US cities $^{10}$. The federally-mandated oxygenated fuel program is not without controversy however. Other studies have shown that the majority of vehicles in use today have low $\mathrm{CO}$ emissions as a result of advances in emission control technology and that in a typical urban area, $50 \%$ of the $\mathrm{CO}$ emissions from the overall vehicular source come from $10 \%$ of the vehicles on the road. The argument is made that oxyfuel programs are costly, since they result in higher fuel costs to the consumer and that many clean car owners are being unnecessarily penalized for the dirty cars driven by a relative few. Opponents further argue that programs should be developed by local agencies that identify those high polluting vehicles with appropriate follow-on measures to bring these vehicles into compliance with $\mathrm{CO}$ emission specifications.

\section{Study Objectives}

The goal of this study was to evaluate the ability of an open-path FT-IR system to detect $\mathrm{CO}$ and $\mathrm{CO}_{2}$ from vehicular sources about 3 meters above the surface of a busy urban intersection. A statistical approach is explored, whereby numerous spectra of vehicular emissions are collected over an extended time interval in order to build an average $\mathrm{CO}$ emission level that is normalized to the amount of fuel consumed through the use of gaseous carbon tracers in the exhaust. The use of a fuel carbon tracer in the exhaust products enables the $\mathrm{CO}$ emissions data to be normalized such that the effects of meteorology and traffic volume during any particular spectral measurement are eliminated from the data. A number of statistical evaluations are carried out on the data to explore the optimum means of representing the $\mathrm{CO}$ emission level and its variability in the data set. Finally, based on the results of these measurements, an evaluation is presented regarding the ability of this proposed method to detect changes in $\mathrm{CO}$ emissions as might be influenced by the implementation of oxyfuel programs in a particular urban area ${ }^{1}$.

\footnotetext{
1 The initial objectives of the study were to measure Albuquerque vehicle $\mathrm{CO}$ emissions during the winter season, when the oxyfuel program was in place and, also during the summer season when oxyfuel was not present in the gasoline. The project funding from the Sandia LDRD office was late however, such that the winter season measurement could not be carried out. The scope of the investigation was changed somewhat as a result of this occurrence.
} 


\section{Experimental Methods}

\section{FT-IR Description}

In this study a bistatic FT-IR spectrometer (MIDAC, Model 2400, Irvine, CA) was used for measurement of vehicular emissions at a busy urban intersection during the morning commute hours. The FT-IR system, shown in Figures 2 and 3, incorporates an infrared (IR) source, receiver-telescope, interferometer, detector and data acquisition computer. The source consisted of a 20 -inch parabolic mirror with a SiC glowbar source positioned at its focal point. The source produces collimated light which was directed across the intersection and into a 10-inch Newtonian telescope. The interferometer/detector unit was mounted on top of and optically aligned with the telescope. The interferometer was a Michelson type with a precision linear motor. The beam splitter and entrance optics material were constructed from zinc selenide. The fixed mirror of the interferometer could be adjusted to insure an alignment normal to the moving mirror for optimized spectral quality. The detector incorporated a liquid-nitrogen cooled, Mercury Cadmium Tellurium (MCT) semiconductor chip, optimized for photon detection in the mid-IR $\left(4000-400 \mathrm{~cm}^{-1}\right)$ region.

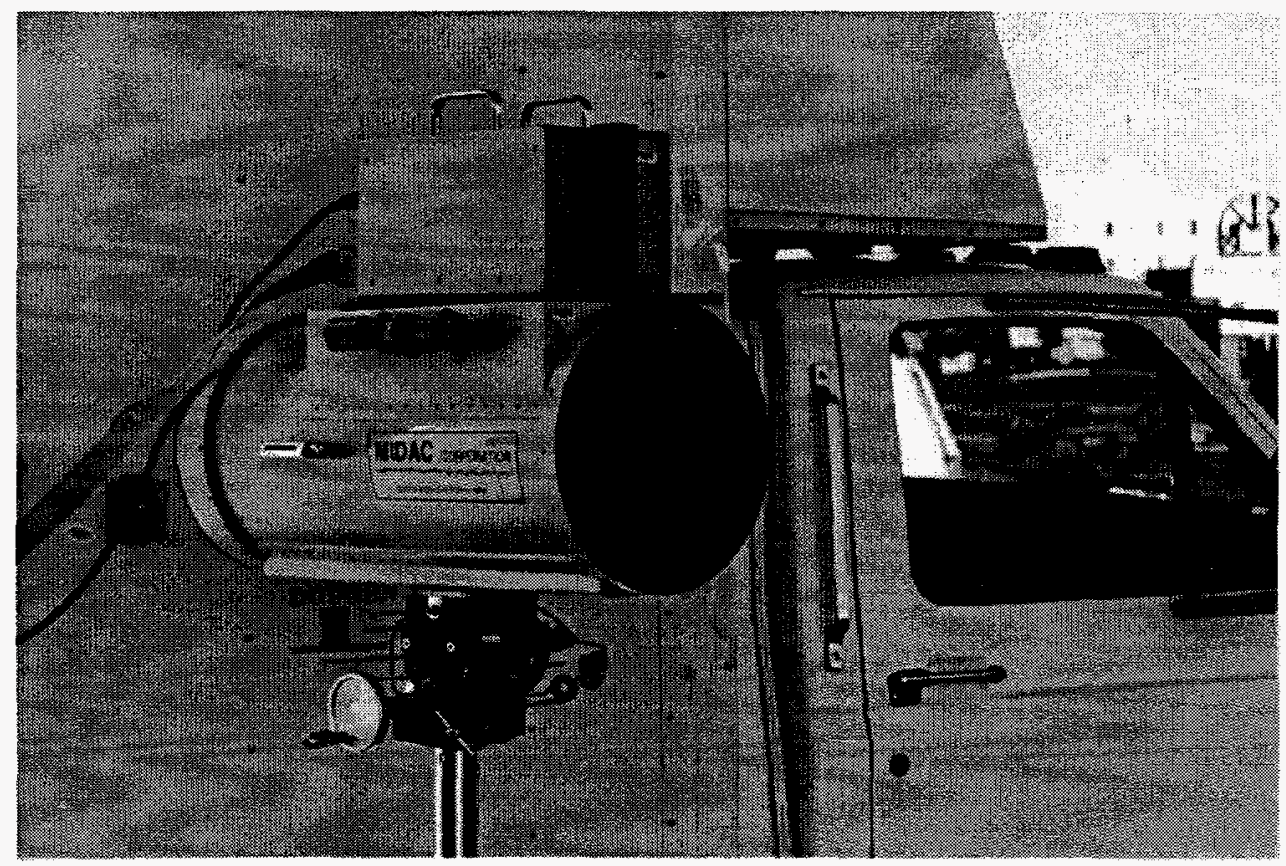

Figure 2 The telescope/interferometer/detector portion of the FT-IR spectrometer. The system was tripod mounted adjacent to a mobile laboratory during the measurement period. 


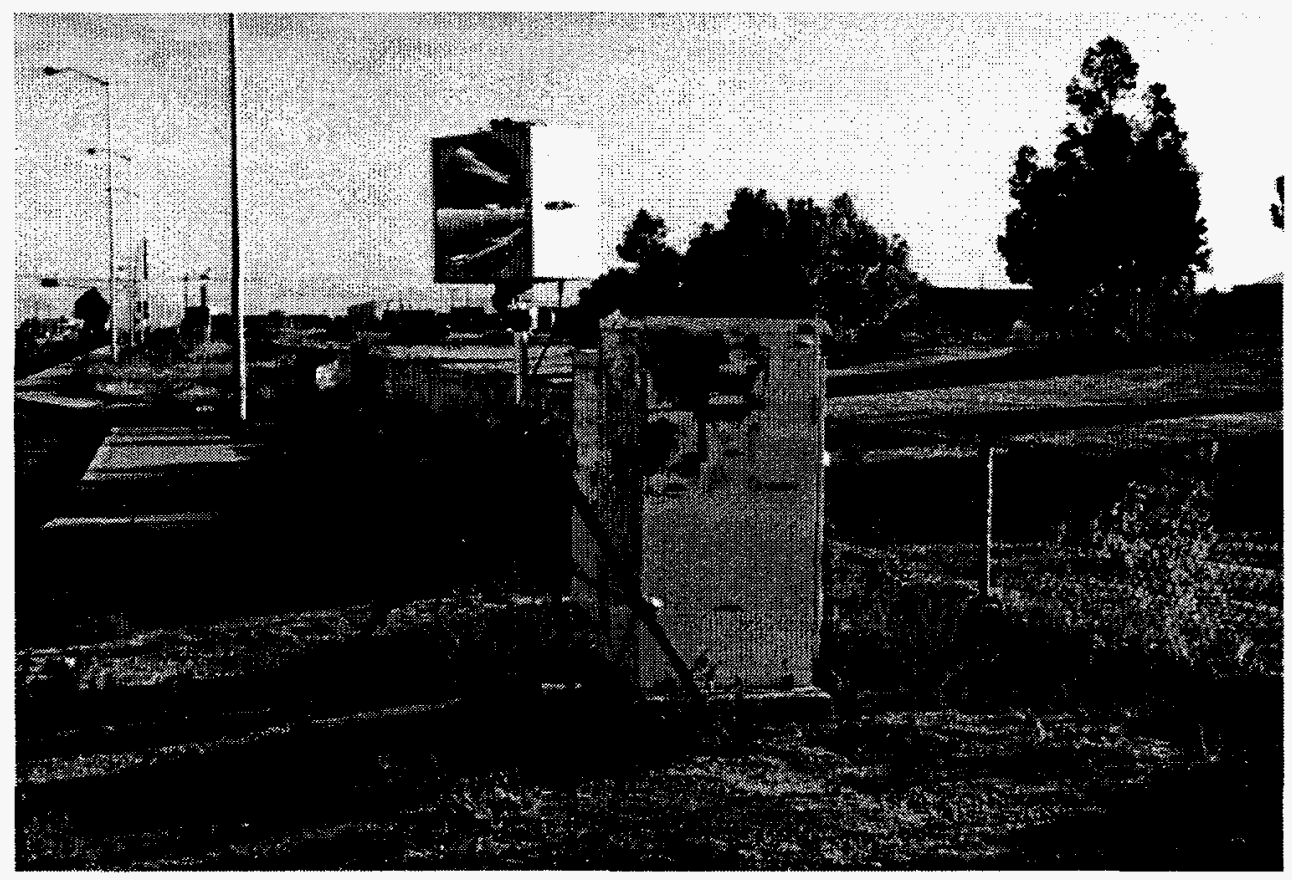

Figure 3 The tripod-mounted source associated with the FT-IR system. The source unit consists of a battery-powered glowbar and a 20 -inch parabolic mirror.

The digitized detector signal was routed via cable from the spectrometer to a PC and was further processed using Lab Calc software (Galactic Industries Corp., Salem, NH). Typical spectrum collection parameters were as shown in Table 2. Some variations from these conditions were employed on selected periods of data collection.

Table 2 Typical Spectrum Collection and Processing Parameters

\begin{tabular}{|l|}
\hline Spectral Resolution: $0.5 \mathrm{~cm}-1$ \\
\hline Spectral Range: $4000-400 \mathrm{~cm}-1$ \\
\hline Number of Interferogram Co-adds per Spectrum: $20-30$ \\
\hline Typical spectrum collection duration: $30-60 \mathrm{~s}$ \\
\hline Beam Path-length: 60 \& $100 \mathrm{~m}$ \\
\hline Fourier Transform Apodization Function: Triangular \\
\hline
\end{tabular}

\section{Site Description}

All spectra were collected during the summer of 1993 at the intersection of San Mateo $\mathrm{NE}$ and Montgomery Blvd. NE located in the Albuquerque's Northeast Heights In 1993 this intersection, shown in Figure 4, was the busiest surface intersection in the city, with traffic counts on the order of 42,000 vehicles per 24 hours on weekdays on each of the north, south, east and west roadways leading into the intersection. The infrared source was positioned in two locations as shown in Figure 5. During initial tests, the source was 
positioned at the northeast corner of the intersection and the receiver telescope at the southwest cormer of the intersection. The beam pathlength for this configuration was 100 m. During later data collection periods, the telescope was positioned at the northwest corner of the intersection with the telescope at the southwest corner. Beam pathlength for this configuration was $60 \mathrm{~m}$. The distance from the center of the beam to the roadway was $2.8 \mathrm{~m}$ at the source end of the beam, and $2.3 \mathrm{~m}$ at the receiver end of the beam. Large trucks and buses would occasionally block the beam; however, conventional automobiles did not block the spectrometer beam during transit through the intersection. Since numerous interferograms were co-added to produce a final spectrum, occasional blockage of the beam during a spectrum collection interval did not result in significant degradation of spectrum quality.
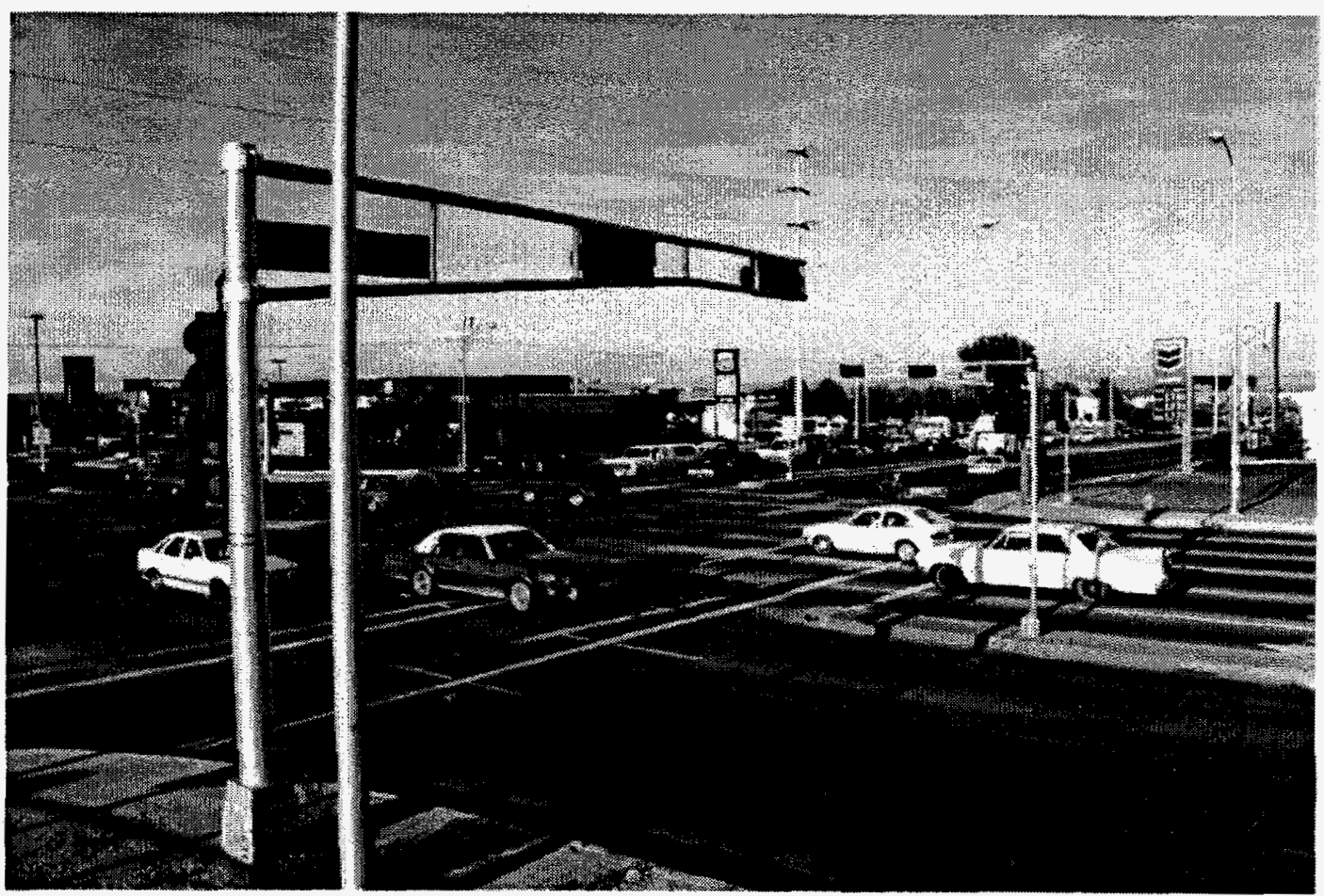

Figure 4 A view of the San Mateo - Montgomery intersection. View is from the northeast corner, near the IR source, looking directly at the FT-IR receiver telescope which is below the "Phillips 66 " sign in the center of the photograph. 
The intersection, as diagrammed in Figure 5, consists of six lanes in all directions (north, south, east and west). In each direction, the lane breakdown was as follows: two left turn lanes, three through lanes, and one right turn lane.

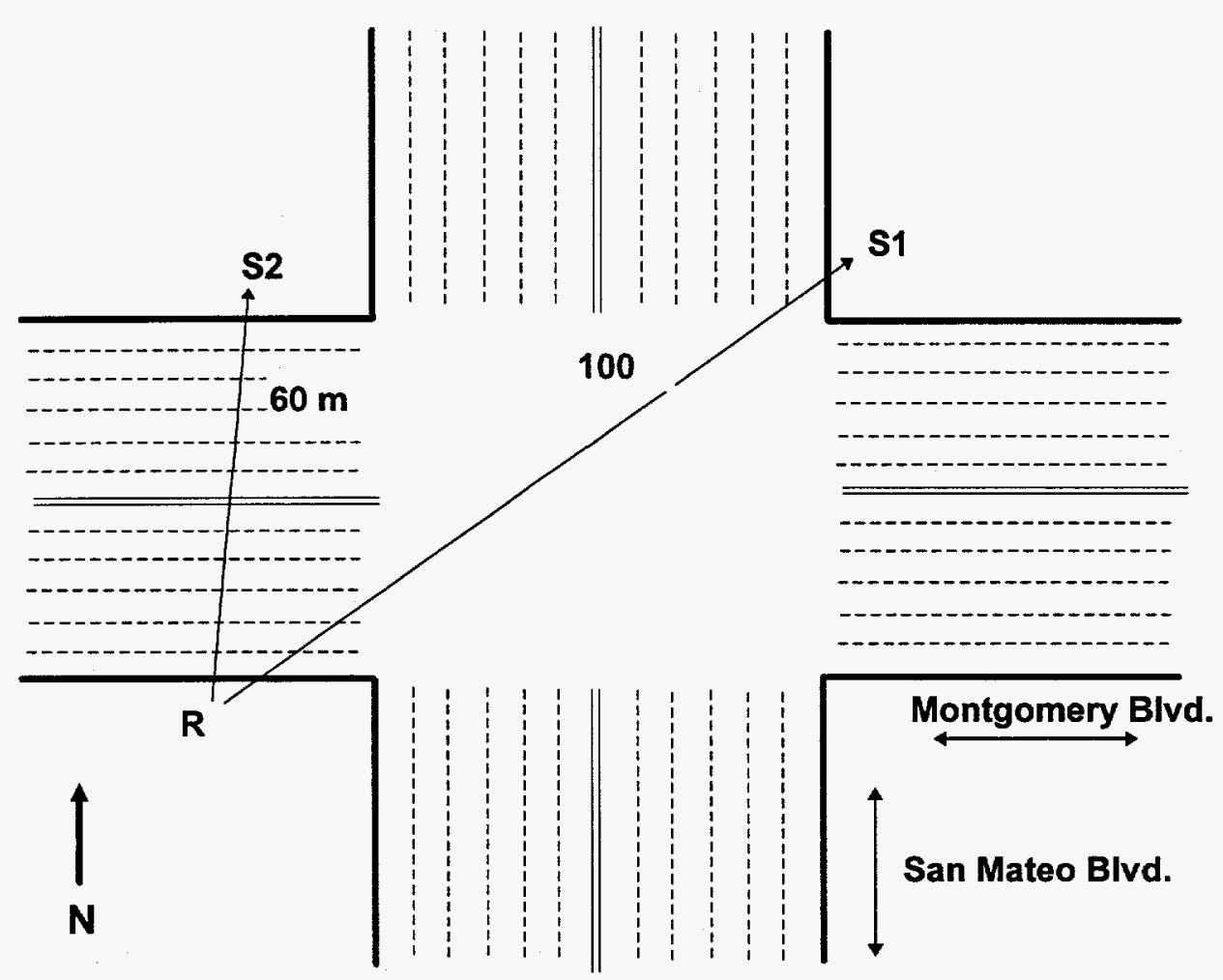

Figure 5 A diagram of the San Mateo-Montgomery intersection. The FT-IR receiver position is denoted by $\mathrm{R}$ and the two source locations used are denoted by S1 and S2.

Spectra were collected during the morning commute period, typically from about 0400 to 1000 hours. Early morning spectra, taken before any significant traffic activity in the intersection, were used as background spectra for subtraction of ambient concentrations of $\mathrm{CO}_{2}$ and $\mathrm{CO}$ during spectral data processing. During a typical measurement period on any particular test day, approximately 50 spectra were collected during peak morning traffic periods. Normally, morning traffic volume begins to increase at about 0530 hours and builds steadily through about 0900 hours. Daytime traffic beyond the morning commute period normally continues at a relatively high rate since this is one of the busiest intersections in the city. 


\section{Data Processing}

Spectral processing was carried out in a batch mode at the conclusion of the field portion of the experiment after all the spectra had been collected. The spectrometer used was a bistatic $^{2}$ system and required spectral corrections for natural atmospheric infrared emissions. These corrections are particularly important when quantitative work is being done is the longer wavelength range of the mid-IR spectrum where natural atmospheric emission is significant. A typical atmospheric emission spectrum taken with the IR source turned off is shown in Figure 6. The atmospheric emission spectrum was collected under test conditions, except that the IR source was turned off. This spectrum was subsequently subtracted from all other ambient air background and test spectra to eliminate the contribution of background atmospheric IR emissions.

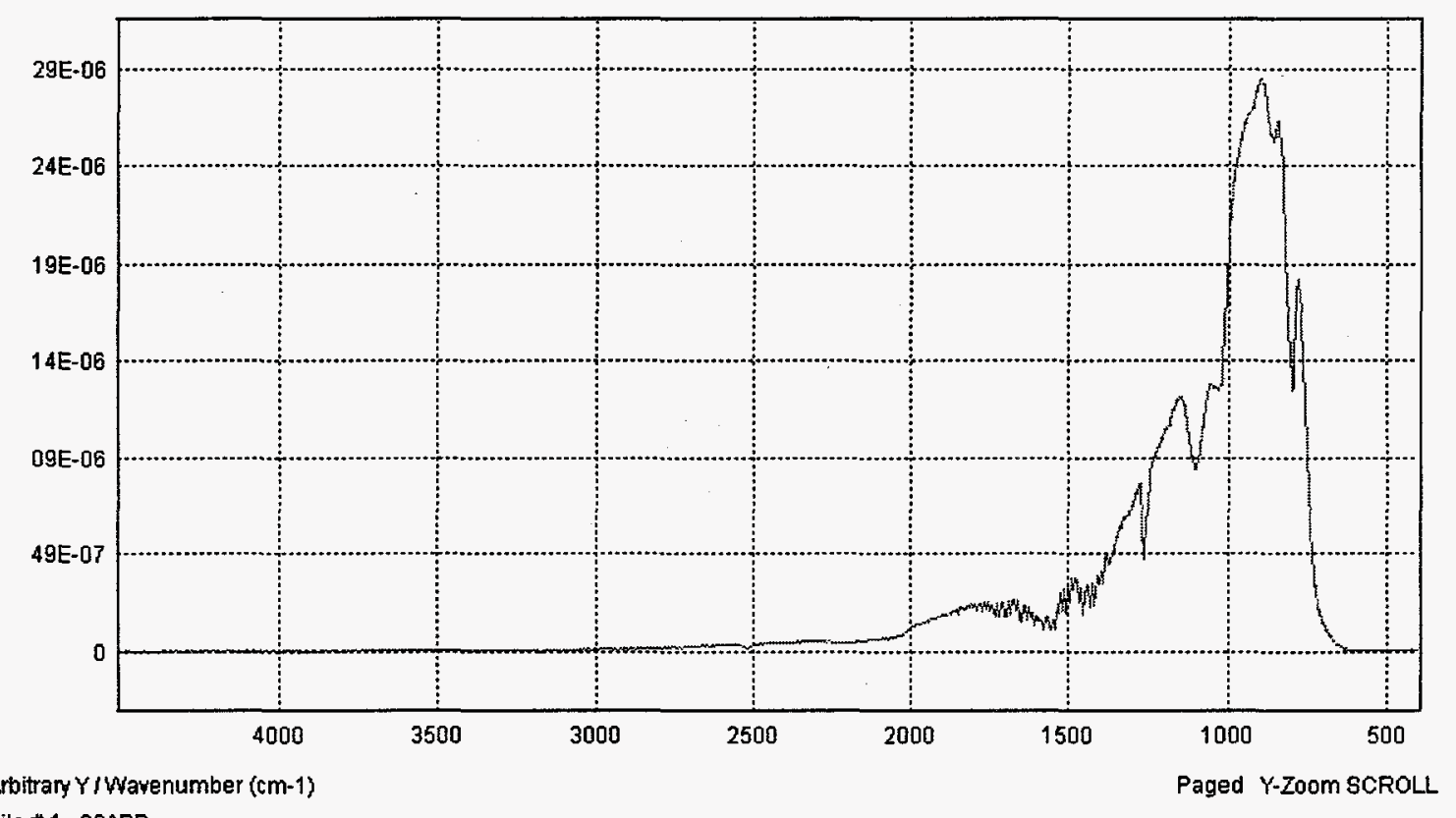

File \#1 : 00ABB

Figure 6 An atmospheric infrared emission spectrum collected under test conditions with the IR source turned off.

Following atmospheric emission spectrum subtraction, each single beam test spectrum was ratioed against a clean ambient air background spectrum that was collected at the intersection very early in the morning prior to traffic activity in the intersection. A typical background air spectrum is shown in absorbance format in Figure 7. All spectra

\footnotetext{
${ }^{2}$ Bistatic configuration denotes that the source is positioned at one end of the beam path and the receiver at the other end. Monostatic systems utilize a combined source and detector at one end and a beam retroreflector at the other end.
} 
were converted to absorbance format prior to further processing. Quantitative analysis was carried out on these spectra assuming Beer's Law relationships (linear variation of spectral absorbance with concentration) were valid. A typical test spectrum ratioed against the reference spectrum is also shown in Figure 7.

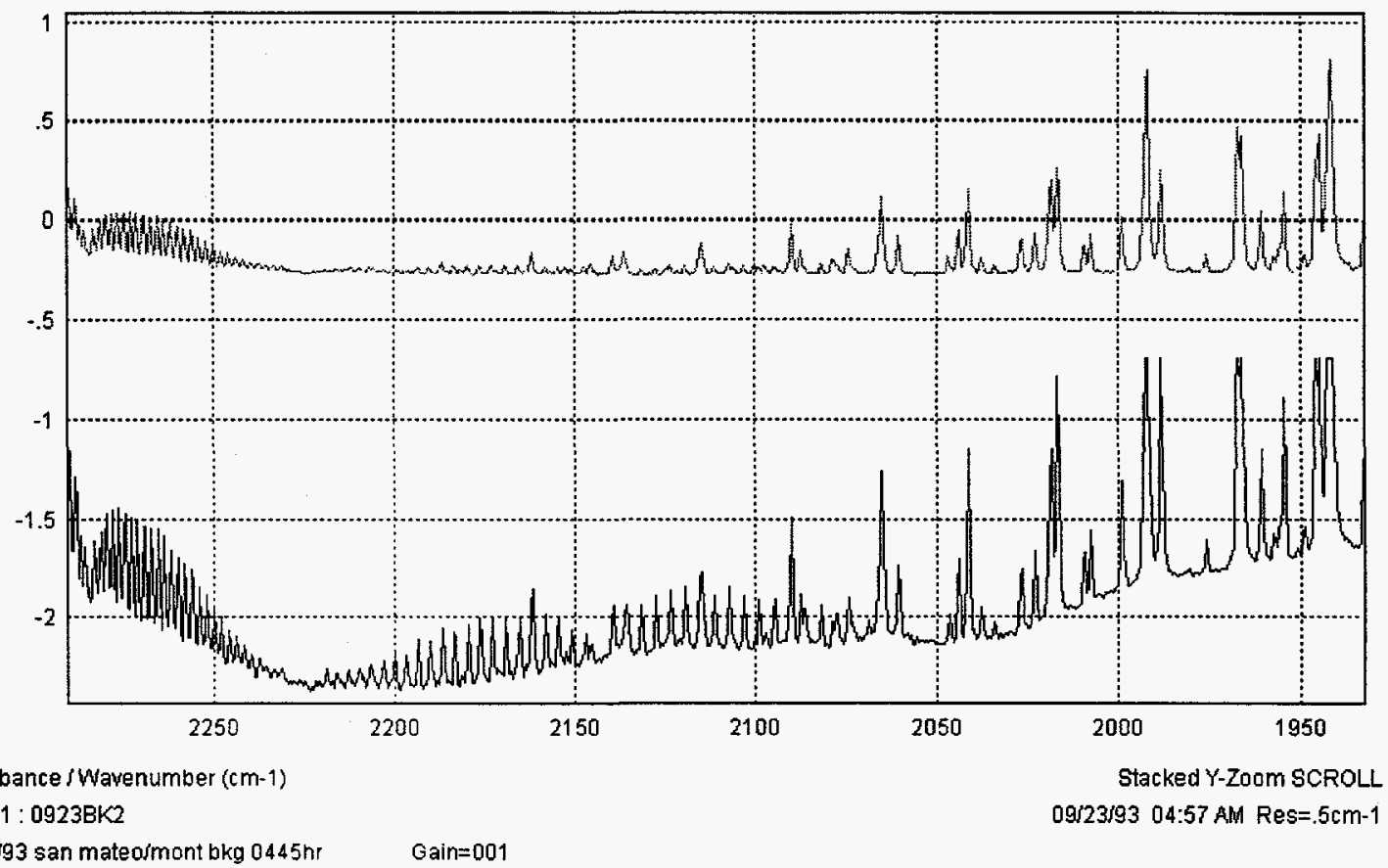

Figure 7 A traffic-free ambient air spectrum (upper) and a high-traffic spectrum (lower) showing spectral features in the $\mathrm{CO}\left(2225-2050 \mathrm{~cm}^{-1}\right)$ absorption band.

A commercially available software package (QASoft, Infrared Analysis, Irvine, CA) functioned as an add-on to GRAMS-386 (Galactic Industries, Salem, NH) for quantitative analysis of the spectra. (GRAMS 386 is the Windows ${ }^{\circledR}$ version of the DOS-based Lab Calc software that was used to collect the spectrum.) Analysis was carried out for $\mathrm{CO}_{2}$, $\mathrm{CO}$ and hydrocarbons measured as n-hexane. An automated processing routine that incorporated spectral subtraction techniques was used to quantify the gases of interest in each spectrum. Quantitation by spectral subtraction is accomplished by using a reference spectrum of the gas of interest and a multiplier in order to bring the absorption feature of interest in the test spectrum back to the spectral baseline. The product of the multiplier and the known concentration of the reference spectrum is a measure of the amount of analyte gas in the test spectrum. Analyte concentrations are determined in units of ppm.m since the spectrum is integrated over the entire beam path-length. Dividing the integrated concentration (ppm.m) by the pathlength $(\mathrm{m})$ used during the measurements yields the average gas concentration in units of $\mathrm{ppm}$ over the entire pathlength. The 
spectral subtraction technique is used to sequentially measure each gas of interest in the analysis routine in the test spectrum. The spectral bands used for quantitative analysis for each of the three gases of interest in this study are given in Table 3.

Table 3 IR Absorption Bands Used in Quantitative Analysis

\begin{tabular}{|l|c|c|c|}
\hline Analyte & $\begin{array}{c}\text { Upper Band } \\
\text { Limit }\left(\mathbf{c m}^{-1}\right)\end{array}$ & $\begin{array}{c}\text { Lower Band } \\
\text { Limit }\left(\mathbf{c m}^{-1}\right)\end{array}$ & $\begin{array}{c}\text { Zero Baseline } \\
\text { Point }\left(\mathbf{c m}^{-1}\right)\end{array}$ \\
\hline Carbon Dioxide & 723 & 718 & 723 \\
\hline Carbon Monoxide & 2170 & 2168 & 2171 \\
\hline n-Hexane & 3000 & 2800 & 2800 \\
\hline
\end{tabular}

\section{Results}

\section{Measurement Summary}

The measurements completed at this particular intersection are summarized in Table 4. Data was collected on four separate mornings. A total of about 250 spectra were collected during all four visits to the intersection.

Table 4 Test Measurement Summary

\begin{tabular}{|l|c|c|}
\hline Date & No. of Test Spectra & Time Interval \\
\hline Jul 30 & 36 & $8: 45$ AM - 11:15 AM \\
\hline Aug 25 & 24 & $6: 00$ AM - 8:30 AM \\
\hline Sep 15 & 43 & $6: 15$ AM -11:30 AM \\
\hline Sep 23 & 84 & $6: 15$ AM - 9:30 AM \\
\hline
\end{tabular}

\section{Spectral Features}

A detailed analysis of the data from September 15 and 23 was undertaken out to assess the variability of the gases of interest and the computed CO-fuel carbon ratio. Typical test spectra are shown in Figures 8 and 9, highlighting the absorption bands used to quantify $\mathrm{CO}$ and $\mathrm{CO}_{2}$ in this study. The fine spectral structure in the $2225-2050 \mathrm{~cm}^{-1}$ region shows $\mathrm{CO}$ absorbance in the range of 0.1 to $0.2 \mathrm{AU}$. A single peak between 2170 and $2168 \mathrm{~cm}-1$ was used for quantitation. A weak absorption peak at $720 \mathrm{~cm}^{-1}$, as noted in Figure 9 was used to quantitate $\mathrm{CO}_{2}$ since most of the other bands are saturated at ambient $\mathrm{CO}_{2}$ concentration levels. 


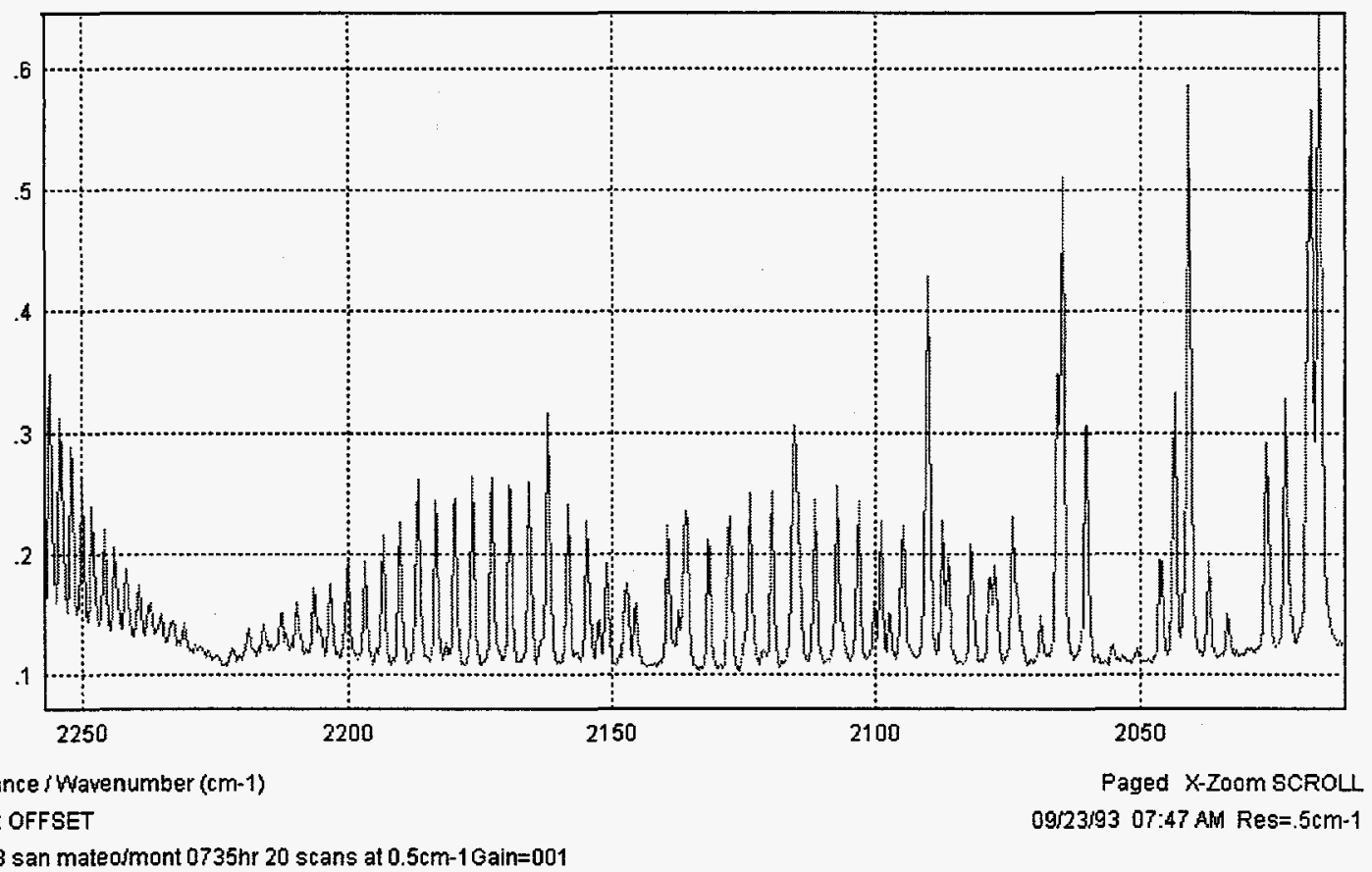

Figure 8 A typical background-corrected test spectrum during a high-traffic period showing $\mathrm{CO}$ absorption features in the $2225-2050 \mathrm{~cm}^{-1}$ band.

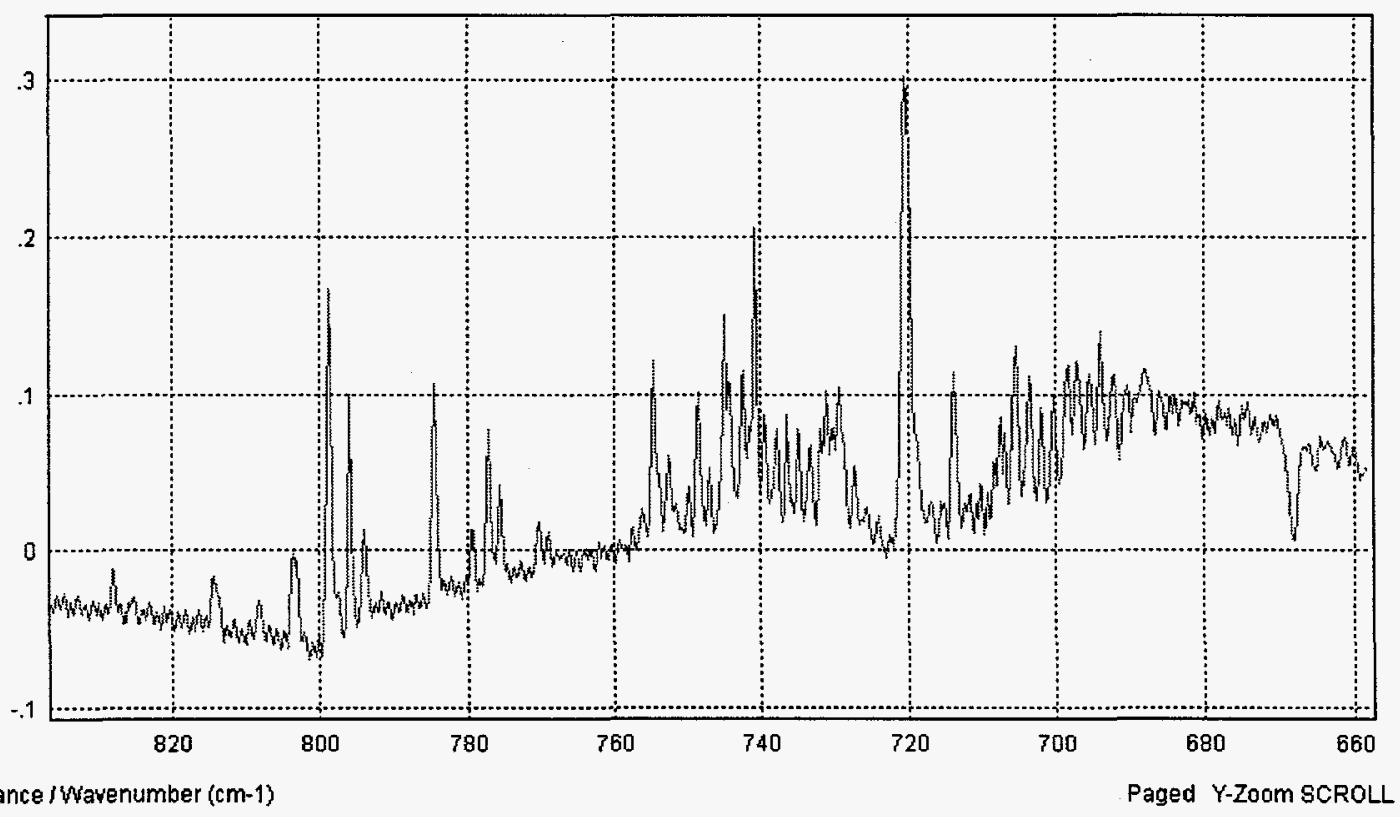

Absorbance / Wavenumber (cm-1)

File \#1:0923TC11

Figure 9 A typical background-corrected test spectrum during a high-traffic period showing $\mathrm{CO}_{2}$ absorption features in the $721-718 \mathrm{~cm}^{-1}$ band. 


\section{Temporal Considerations}

Plots of $\mathrm{CO}$ and $\mathrm{CO}_{2}$ levels as a function of time of the morning of September 23 are given in Figures 10 and 11. In each case, the data are background corrected for ambient $\mathrm{CO}_{2}$ and $\mathrm{CO}$. This is particularly important for $\mathrm{CO}_{2}$ since ambient levels range from 350 to $400 \mathrm{ppm}$. In this study, the assumption was made that the background $\mathrm{CO}_{2}$ was constant and that it was adequately represented by the measurements made at the intersection very early in the morning ( $\sim 0400$ hours), prior to any significant vehicular activity on the local roadways.

The $\mathrm{CO}_{2}$ levels are observed to rise between 630 and $700 \mathrm{AM}$ to a level about $20 \mathrm{ppm}$ above the background level. Considerable variation is observed between spectra, most likely a result of irregular traffic flow and the formation of periodic traffic queues at the intersection during periods of red lights. Peak concentrations are generally observed at about $0800 \mathrm{hr}$. with a gradual drop off until about 1000 hours, however periodic high excursions are noted during this time interval as well. The time series plot for CO looks very similar, with a gradual rise occurring between the hours of 0600 and about 0800 . Periodic high excursions are also noted. The $\mathrm{CO}$ levels begin to drop off shortly after 0800 hours and continue their decline until 1000 hours when the measurement cycle was completed. Carbon monoxide concentration levels typically ranged from a low of about 1 $\mathrm{ppm}$ to a high of $6 \mathrm{ppm}$. Background $\mathrm{CO}$ levels measured prior to periods of high traffic activity were on the order of $0.1 \mathrm{ppm}$.

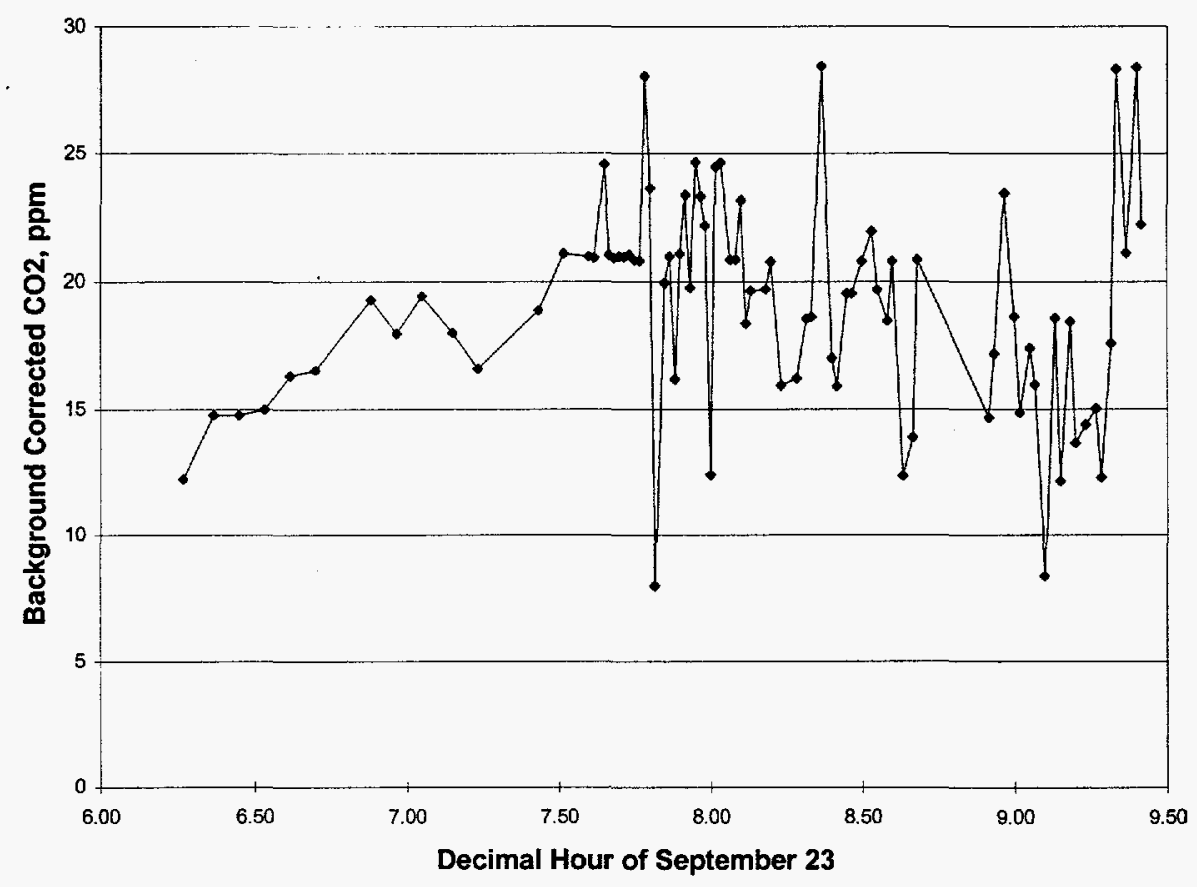

Figure 10 Background-corrected $\mathrm{CO}_{2}$ concentrations for Sept. 23, AM. 


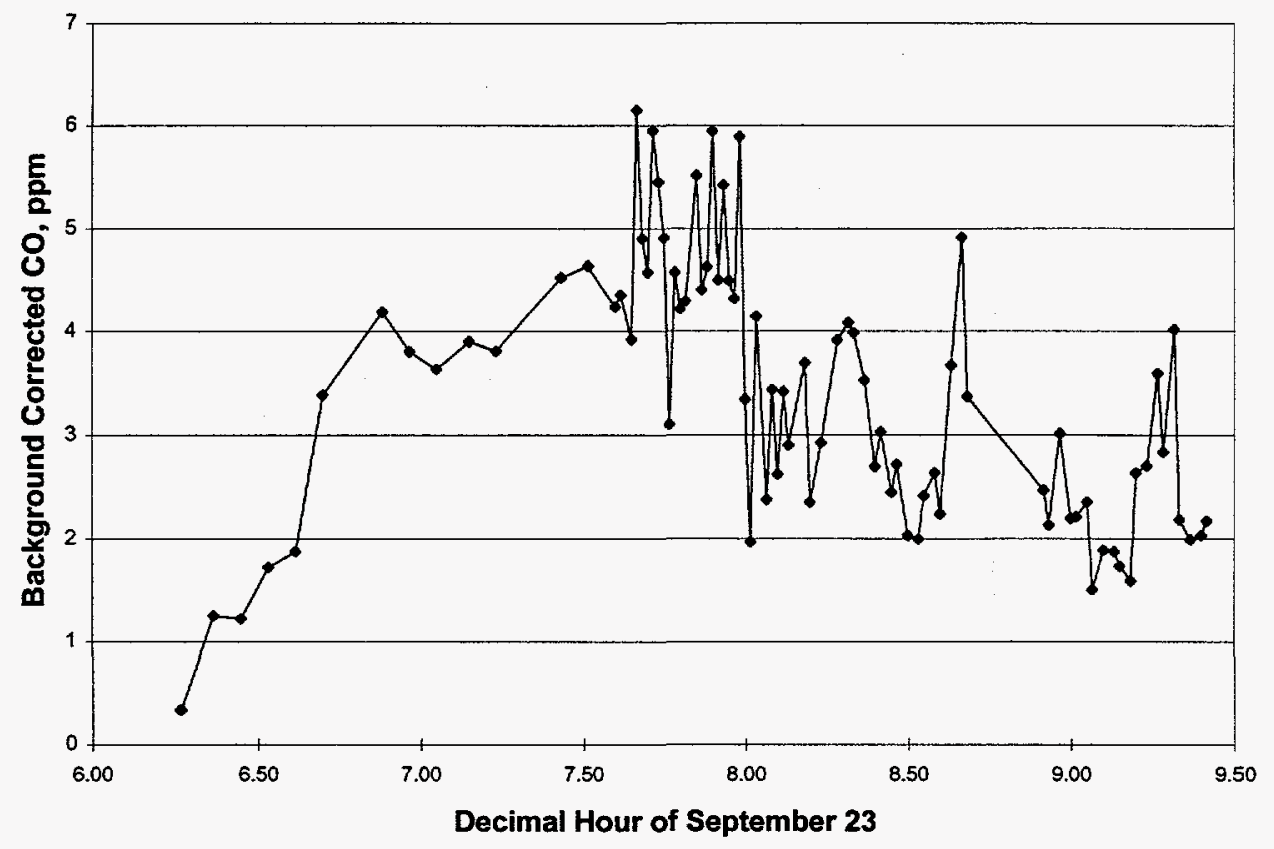

Figure 11 Background-corrected CO concentrations for Sept. 23, AM.

Although a quantitative analysis was carried out on all spectra for hydrocarbons as nhexane, all results were below the detection level of the spectrometer as it was configured for this particular test. For this experimental configuration the detection level for nhexane and other similar hydrocarbons was about $0.150 \mathrm{ppm}$. The fact that hydrocarbons were not detected is not surprising based on the following observations. From the data presented in Table 1, typical tailpipe emissions of CO are about $5 \%(50,000 \mathrm{ppm})$, and typical above-background $\mathrm{CO}$ concentrations at spectrometer beam level above the intersection were on the order of $5 \mathrm{ppm}$. Thus, the dilution factor from tailpipe concentration to beam-level air concentration was on the order of $10^{4}$. A similar dilution factor was obtained when the same calculation was carried out for $\mathrm{CO}_{2}$. Hydrocarbon tailpipe concentrations are on the order of $400-500 \mathrm{ppm}$. A $10^{4}$ dilution factor applied to this hydrocarbon concentration level results in a concentration of about $0.040-0.050 \mathrm{ppm}$ at spectrometer beam level. Such levels are about one-third the detection level of the system as configured for this experiment and thus would not be detected.

\section{CO-Fuel Carbon Ratios}

A plot of the CO-fuel carbon ratio for the September 23 measurement period is shown in Figure 12. The ratio was calculated using the following formula:

$$
R A T I O=\frac{[\mathrm{CO}]}{[\mathrm{CO}]+\left[\mathrm{CO}_{2}\right]}
$$


where, RATIO is the aggregate $\mathrm{CO}$ emission factor, and $[\mathrm{CO}]$ and $[\mathrm{CO} 2]$ are the background-corrected concentration levels of $\mathrm{CO}$ and $\mathrm{CO}_{2}$ in units of ppm. As noted earlier, the combination of $\mathrm{CO}$ and $\mathrm{CO}_{2}$ represents a measure of total fuel carbon. The resulting ratio is a measure of the overall emission factor of $\mathrm{CO}$ (in grams of $\mathrm{CO}$ carbon to grams of fuel carbon) from the aggregate vehicle source contributing to the measured air above the intersection at any particular point in time. By the use of this ratio, temporal variations relating to source strength and meteorology are removed from the data. The time series plot of the $\mathrm{CO}$-fuel carbon ratio has similar characteristics to the $\mathrm{CO}$ and $\mathrm{CO}_{2}$ plots discussed earlier. Considerable variation is observed in the ratio throughout the measurement interval, and an overall decreasing trend is observed after about 0730 hours. The observed decline in the ratio may be partially attributable to the presence of fewer engines in the cold-engine operational mode (with a corresponding increase in air-fuel ratio and combustion efficiency) as the morning commute period progresses forward in time.

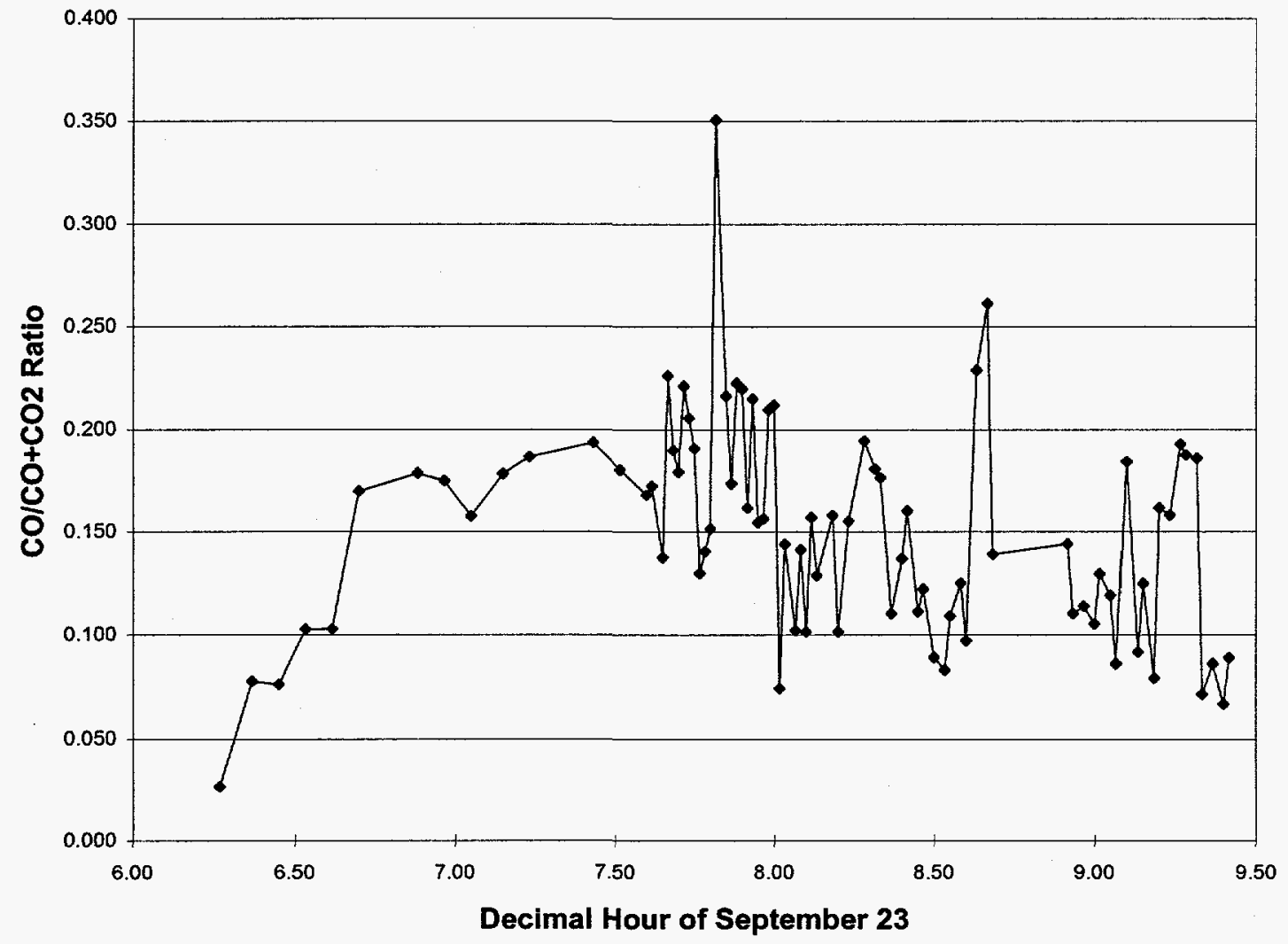

Figure 12 A plot of the CO-fuel carbon ratio for all measurements on Sep. 23 AM. 


\section{Statistical Analyses}

A variety of statistical analyses were carried out on the collected data sets to gain a better understanding of the degree to which the $\mathrm{CO}$-fuel carbon ratio varied throughout the study period and to assess how the data were distributed.

\section{Descriptive Statistics}

A summary of descriptive statistics for each of the three variables of interest, namely $\mathrm{CO}_{2}, \mathrm{CO}$, and CO-fuel carbon ratio for the data collections on September 15 and 23 is given in Table 5 .

Table 5 Summary Statistics for $\mathrm{CO}$, $\mathrm{CO}$ and the $\mathrm{CO}$-Fuel Carbon Ratio

\begin{tabular}{|l|c|c|c|}
\hline Parameter & $\begin{array}{c}\text { CO2 } \\
\text { (ppm) }\end{array}$ & $\begin{array}{c}\text { CO } \\
\text { (ppm) }\end{array}$ & Ratio \\
\hline Valid N & 118 & 118 & 118 \\
\hline Mean & 22.77 & 4.06 & 0.149 \\
\hline Standard Deviation & 12.67 & 2.73 & 0.049 \\
\hline Median & 19.69 & 3.42 & 0.152 \\
\hline Maximum & 58.70 & 12.38 & 0.351 \\
\hline Minimum & 5.257 & 0.330 & 0.026 \\
\hline $\begin{array}{l}\text { Mean Upper 95\% } \\
\text { Confid. Interval }\end{array}$ & 25.08 & 4.56 & 0.158 \\
\hline $\begin{array}{l}\text { Mean Lower 95\% } \\
\text { Confid. Interval }\end{array}$ & 20.46 & 3.56 & 0.140 \\
\hline
\end{tabular}

Of particular interest are the summary statistics of the Ratio variable. The overall average is 0.149 , a value consistent with the expected ratios discussed previously. As noted in Figure 1 and the accompanying text, an average ratio of 0.14 corresponds to a vehicle airfuel ratio of about 14. The typical stoichiometric ratio for an internal combustion engine is about 14.6. In general, cold temperature operation of an automobile engine, such as encountered in the early morning commute period, results an air-fuel ratio below stoichiometric since the fuel is less volatile and requires less combustion air. On the basis of these considerations, the observed average ratio of 0.15 appears to be on the low side of stoichiometric point as would be expected. This observation lends overall credibility to the measurements and the computed ratio.

The confidence interval about the mean ratio is quite small--about $\pm 6 \%$ of the mean value. The significance of the confidence interval is that the true population mean (the average ratio that would be obtained if an infinite number of measurements were made) would fall within this interval with $95 \%$ certainty. The small interval is in large part a result of the fact that a large number of measurements, nearly 120 , are used to compute the mean value. 


\section{Tests for Normal Distribution}

A further evaluation was carried to assess the extent to which the measured variables are normally distributed. Histograms of all $\mathrm{CO}_{2}$ and $\mathrm{CO}$ observations are given in Figures 13 and 14. A normal curve superimposed on the two sets of data show that these species are not normally distributed. The shape of the distribution appears to be log normal in fact.

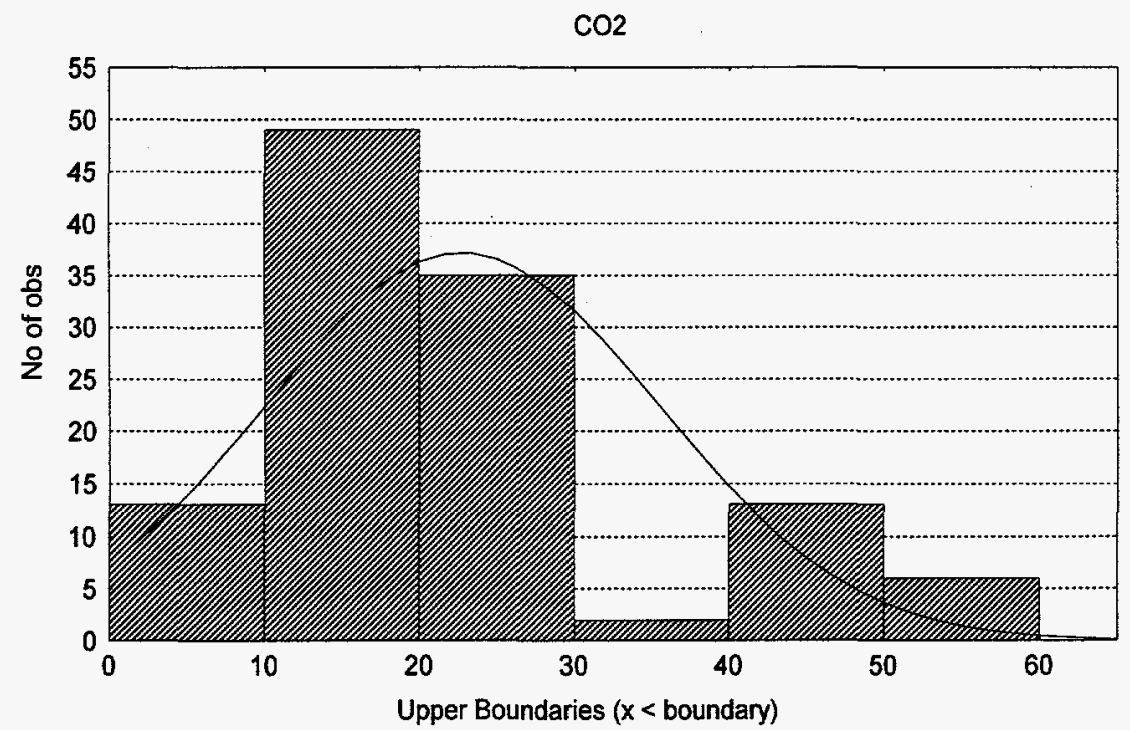

Figure $13 \mathrm{~A}$ histogram of all $\mathrm{CO}_{2}$ measurements made during periods of high traffic activity. The solid line depicts a normal distribution.

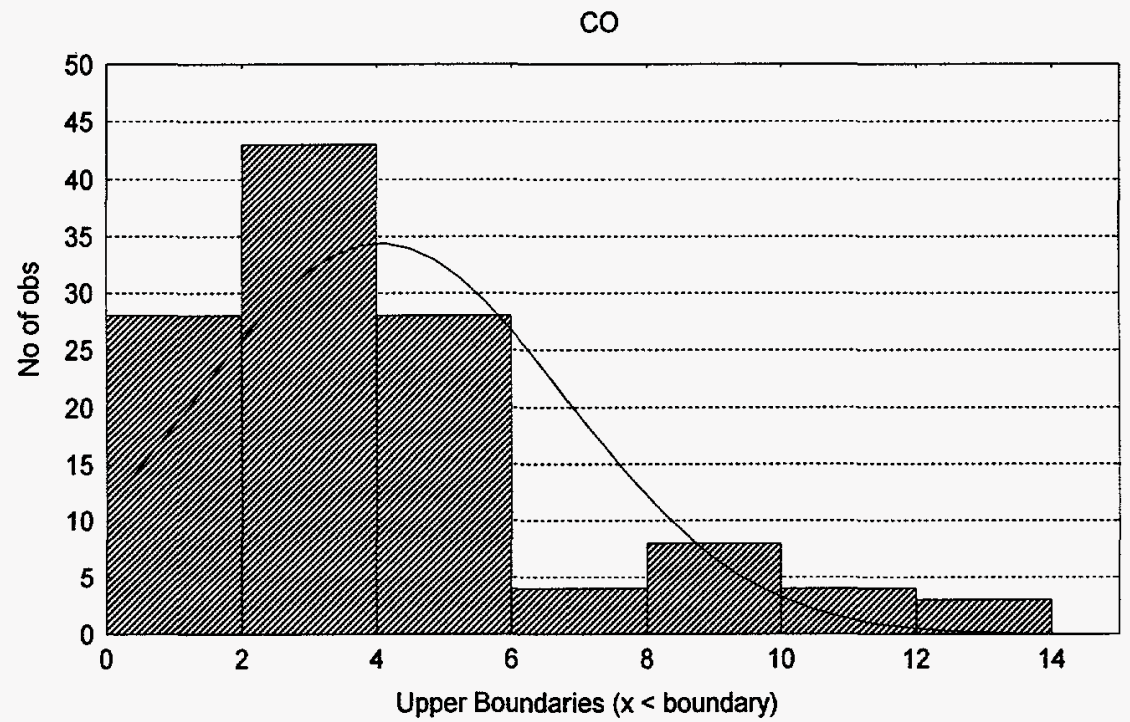

Figure 14 A histogram of all $\mathrm{CO}$ measurements made during periods of high traffic activity. The solid line depicts a normal distribution. 
A histogram of the computed CO-fuel carbon ratio is shown in Figure 15 and a normal probability plot is shown in Figure 16. A normal distribution curve is superimposed on the data, showing a relatively good comparison between the data and the curve. The plot in Figure 16 is constructed by first computing and rank ordering the residuals of all observations from the mean value of the distribution. From these ranks, $\mathrm{z}$ values (standardized values of the normal distribution) are computed by assuming that the observed distribution is normal. The $\mathrm{Z}$ values are then plotted on the $\mathrm{Y}$-axis along with the corresponding residuals on the $\mathrm{X}$-axis. If the distribution is normal, the points should fall on the diagonal line. In this particular case, with the exception of a few outliers at the distribution extremes, all points fall in close proximity to the line, suggesting that the data are in fact normally distributed. The results of a Shapiro-Wilk's W test for normality yields a quantitative result which corroborates this graphical observation of normal distribution ${ }^{11}$. This result is of particular importance in the context of additional statistical tests carried out on the data as discussed in following sections.

RATIO

K-S $d=.04996, p>.20$; Lilliefors $p>.20$

Shapiro-Wilk $W=.97962, p<.4579$

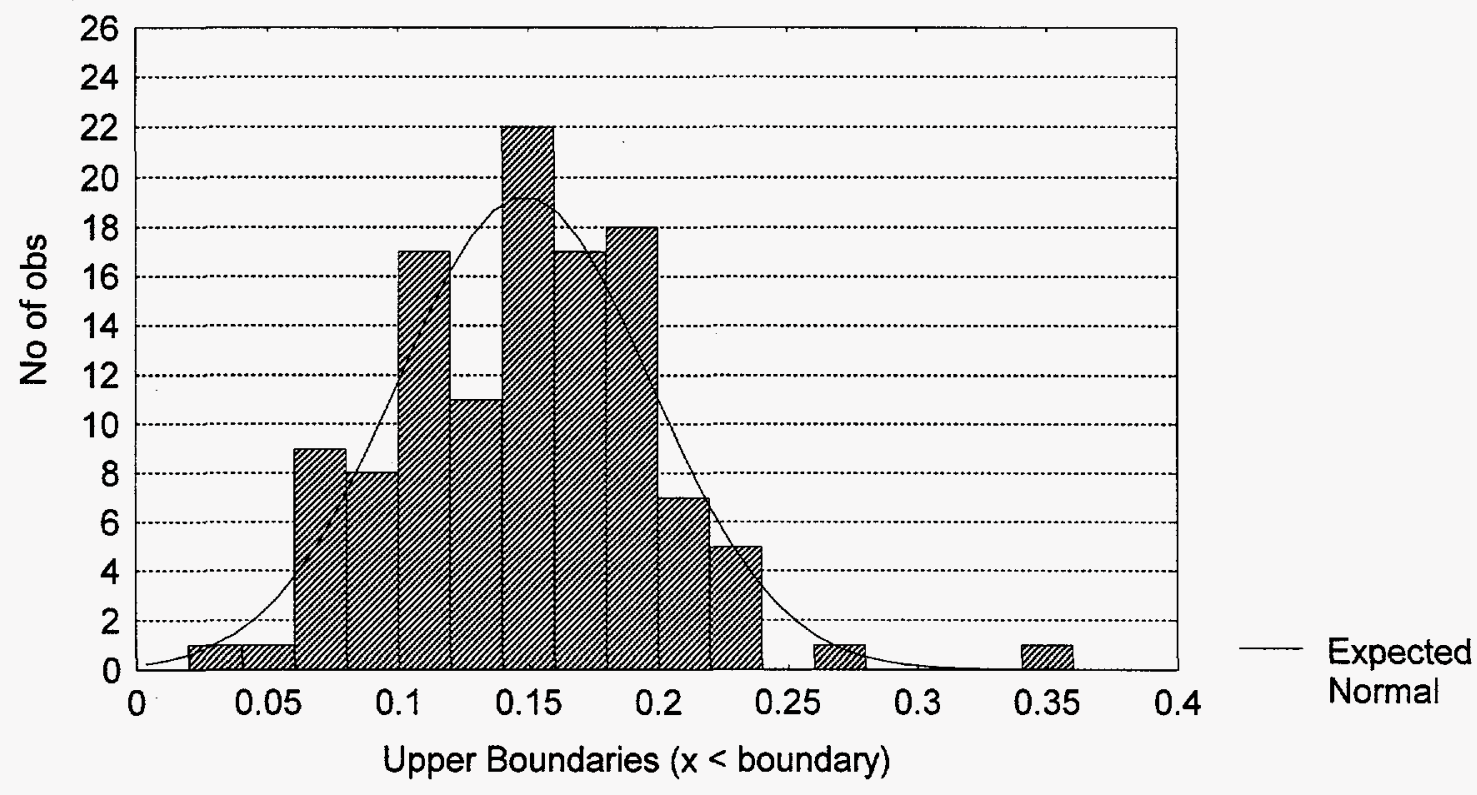

Figure 15 A histogram for all computed values of the $\mathrm{CO}$-fuel carbon ratio. The Shapiro Wilk's W test result, shown in the header indicates that the data are normally distributed. 
Normal Probability Plot

RATIO

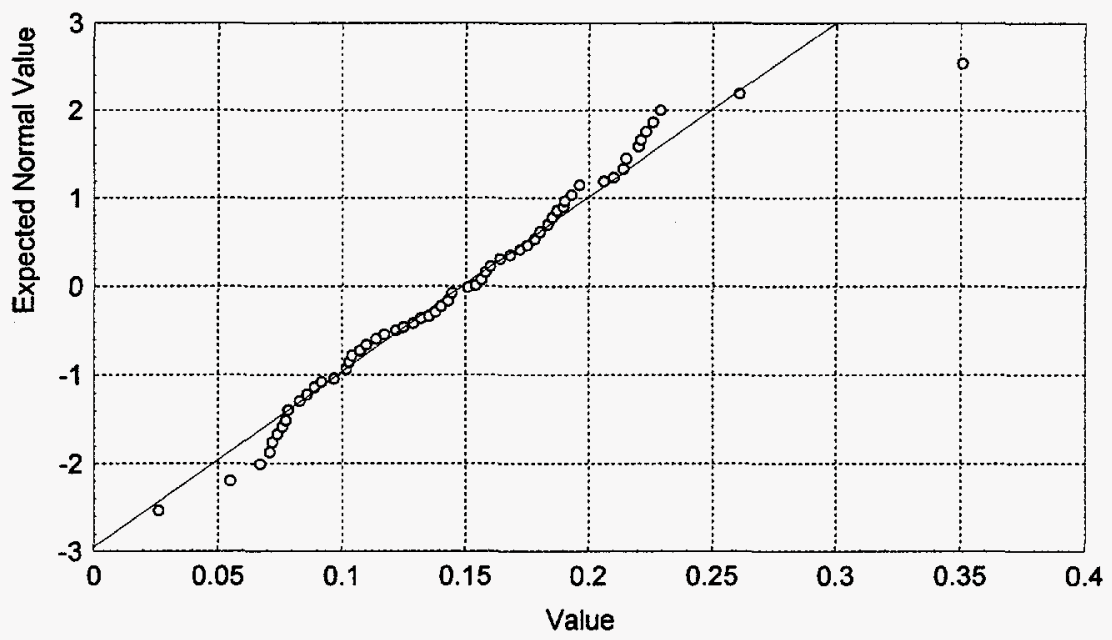

Figure 16 A normal probability plot for the CO-fuel carbon Ratio. See accompanying text for a description and interpretation of the plot.

\section{Correlation Analysis}

The correlation of $\mathrm{CO}$ with the fuel carbon tracer $(\mathrm{CO}+\mathrm{CO} 2)$ variable is shown in Figure 17. The correlation between these two variables is high (correlation coefficient $=0.909$ ), yielding further evidence that the measured species are inter-related and not a set of random observations.

$$
\begin{gathered}
\mathrm{CO}+\mathrm{CO} 2 \text { vs. } \mathrm{CO} \\
\mathrm{CO}=-.3571+.16457^{*} \mathrm{CO} \_\mathrm{CO} 2 \\
\text { Correlation: } r=.90888
\end{gathered}
$$

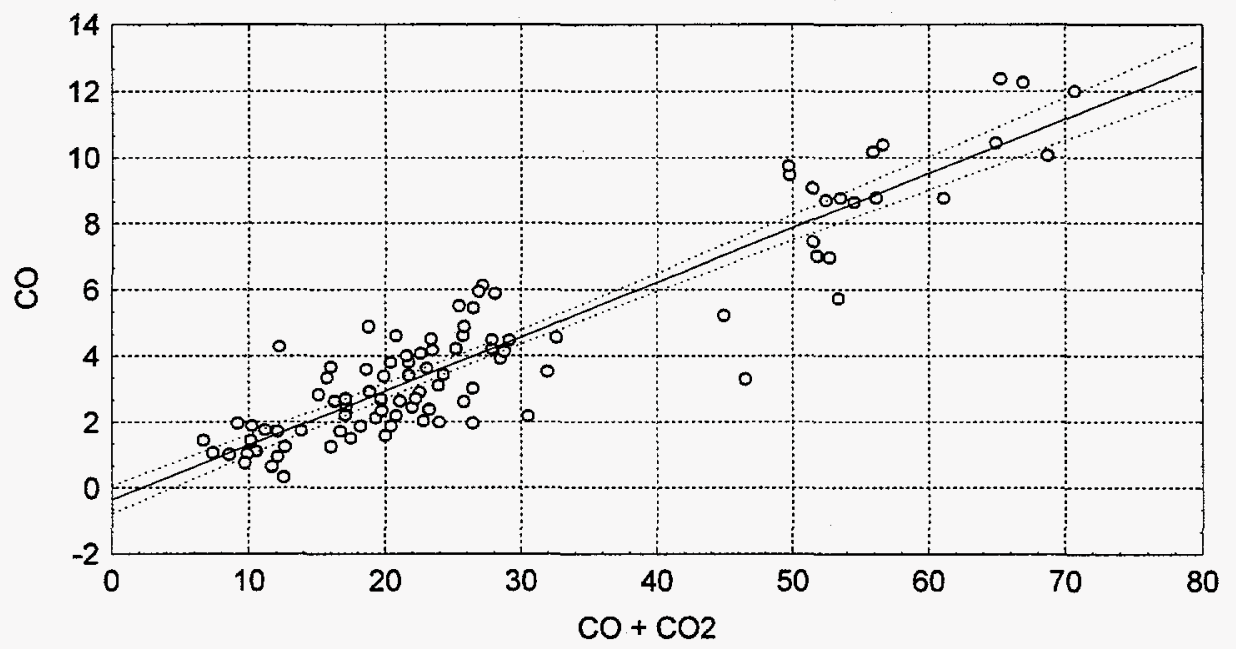


Figure 17 A correlation plot of all measured $\mathrm{CO}$ data vs. $\mathrm{CO}+\mathrm{CO}_{2}$. The axes units are ppm.

\section{T-Test for Independent Observations}

In order to assess the day-to-day stability of the average ratio, the data from September 15 and September 23 were divided into separate groups and the mean ratios were statistically compared using the $t$-test for independent samples. The $t$-test can be used to test for a difference in the means of the ratios computed for two separate sampling days or intervals. In this case, the expectation is that the means from the two different days should not differ since the average fuel mix and vehicle type passing through the intersection is unchanged over the short time interval between measurements. The t-test produces a $\mathrm{p}$ value which can be interpreted as the probability of an error in calling the two means statistically different when in fact they are not. The summary data for the two days used in this test are given in Table 6. Normally, a p value of 0.05 or less is understood to indicate that the two means can be called statistically different with $95 \%$ or greater certainty. In this test, the $p$ value is 0.68 indicating the converse of the above-namely, that the two means are statistically equivalent and are derived from the same population.

Table 6 Summary CO-fuel carbon Ratio Statistics for September 15 and 23

\begin{tabular}{|l|c|c|}
\hline Parameter & Sep 15 Data & Sep 23 Data \\
\hline Ratio - Mean & 0.150 & 0.145 \\
\hline Ratio - Standard Deviation & 0.052 & 0.040 \\
\hline T-Test Degrees of Freedom & \multicolumn{2}{|c|}{116} \\
\hline T Value & \multicolumn{2}{|c|}{-0.409} \\
\hline$p$ (2-Sided) & \multicolumn{2}{|c|}{0.68} \\
\hline
\end{tabular}

\section{Method Sensitivity to Detect CO Emission Reduction}

As noted earlier in this report, the initial intent of this project was to conduct a similar sampling exercise during periods when Albuquerque's winter-season oxyfuel program was in place in order to assess the overall effectiveness of an oxyfuel program. Funding complications prevented that course of action however. Alternatively, and in the absence of a second set of measurements, a final question can be raised in light of the collected data: Could reduced $\mathrm{CO}$ emissions from vehicular sources as a result of an oxyfuel program be detected by this remote sensing method? And, if so, how small a change could be detected with a high measure of certainty? To answer these questions, the data from this effort were be used to estimate how small a change in the CO-fuel carbon ratio could be detected with $95 \%$ certainty. Recent EPA studies on the benefits of oxyfuels report an overall $17 \%$ reduction in the $\mathrm{CO}$ emissions from vehicles burning oxygenated fuels. Such a reduction, would correspond to a decrease in the CO-fuel carbon ratio from the measured value of 0.150 for a non-oxyfuel condition to a value of 0.125 in an oxyfuel 
condition. On the basis of the data collected in this study, an overall $17 \%$ reduction in $\mathrm{CO}$ emissions from vehicles could be detected with a high (>95\%) degree of confidence. Furthermore, the minimum percent change in the average $\mathrm{CO}$-fuel carbon ratio that could be detected with $95 \%$ certainty would be $5.2 \%$. This corresponds to a reduction in the ratio from 0.150 to 0.142 . The assumptions associated with the above estimates are as follows:

- A one-sided probability distribution is assumed since the fuel chemistry dictates that only a reduction in $\mathrm{CO}$ emissions should occur with oxygenated fuel. That is, one would not expect to see an increase in $\mathrm{CO}$ emissions, so a difference in that direction can be ruled out.

- The data from the measurements during the oxyfuel season would be required to have a sample size on the order of 120 measurements, similar to the number of measurements used in this analysis.

- The data from the oxyfuel season measurement are also assumed to normally distributed.

\section{Conclusions}

This study utilized an open-path FT-IR spectrometer over a busy Albuquerque intersection to measure both $\mathrm{CO}$ and $\mathrm{CO}_{2}$ emitted from vehicles passing through the intersection during the morning commute period. Study results reveal that both $\mathrm{CO}$ and $\mathrm{CO}_{2}$ can be detected above background levels during periods of high traffic volume in the morning commute period. Hydrocarbon emissions, although suspected to be present, were below the detection levels of the spectrometer. In light of the observed dilution factor between typical tailpipe concentrations of $\mathrm{CO}$ and those observed at spectrometer beam level above the intersection, the inability to detect hydrocarbons was as expected

The sum of $\mathrm{CO}$ and $\mathrm{CO}_{2}$ was used as a fuel carbon tracer since carbon is conserved in the combustion reaction and $\mathrm{CO}$ and $\mathrm{CO}_{2}$ account for over $99 \%$ of the carbon products emitted from the tailpipe. The ratio of $\mathrm{CO}$ to $\mathrm{CO}+\mathrm{CO}_{2}$ was computed and used as an estimate of the average $\mathrm{CO}$ emission factor for the vehicles passing through this intersection. The mean CO-fuel carbon ratio for a non-oxyfuel period was 0.149 with a $95 \%$ confidence interval of \pm 0.009 . The value of this ratio is consistent with expectations based upon typical air-fuel ratios for the overall vehicle fleet during the morning commute period.

Statistical analyses on the data set reveal that a minimum increment of about $5 \%$ in the CO-fuel carbon ratio could be detected with $95 \%$ reliability, assuming that approximately 120 spectra were collected during periods of oxyfuel usage. The overall $17 \%$ reduction in vehicular CO emissions estimated by the US EPA following a number of studies in various US urban areas using oxygenated fuels could easily be detected by this method. 
The remote sensing FT-IR approach offers certain advantages over more costly and time consuming $\mathrm{CO}$ emission assessment measures such as individual exhaust pipe testing. By design, the method yields an aggregate measure of vehicle performance which may be useful for the development of more accurate emission inventories for specific urban locales. The measurements can be made easily over the period of days or weeks. Recent advances in instrument control software also enable automated operation and data processing further reducing manpower costs associated with data collection and processing. 


\section{References}

1 Spellicy, R. L., W. L. Crow, and J. A. Draves, 1991; "Spectroscopic Remote Sensing," Spectroscopy:5:1-12.

${ }^{2}$ Grant, W. B., R. H. Kagan, W. A. McClenny, 1992; “Optical Remote Measurement of Toxic Gases," Journal of the Air and Waste Management Association, 42:18-30.

3 Stedman, D. H., Yi Zhang, G. A. Bishop, P. L. Guenther, S. P Beaton, 1993; “On-Road Hydrocarbon Remote Sensing," Paper No. 93-WP-102.05, Air and Waste Management Association Annual Meeting, Denver, CO.

${ }^{4}$ Stephens, R. D., and S. H. Cadle, 1991; "Remote Sensing Measurements of Carbon Monoxide Emissions from On-Road Vehicles, "Journal of the Air and Waste Management Association, 41:39-46.

5 Yi Zhang, Stedman, D. H., G. A. Bishop, P. L. Guenther, S. P Beaton, and J. E. Peterson, 1993; "On-Road Hydrocarbon Remote Sensing in the Denver Area," Environmental Science and Technology, 27:1885-1891.

${ }^{6}$ US EPA Office of Mobile Sources, Publication No. EPA 400-F-95-005, 1995 ; (www.epa.gov/omswww/03-co.html), Ann Arbor, MI.

7 Seinfeld, J. H., 1986; Atmospheric Chemistry and Physics of Air Pollution, John Wiley and Sons, New York, pp 77-104.

${ }^{8}$ Heywood, J. B., 1988; Internal Combustion Engine Fundamentals, McGraw Hill, New York, pp567-625.

${ }^{9}$ Clean Air Act as Amended, 1970; U. S. Government Printing Office, Washington D.C.

${ }^{10}$ US EPA Office of Mobile Sources, Publication No. EPA 420-F-95-007, 1995; (www.epa.gov/omswww/rfgnew.html), Ann Arbor, MI.

11 Shapiro, S, S., M. B. Wilk, and H. J. Chen, 1968; "A comparative study of various tests for normality," Journal of the American Statistical Association, 63:1343-1372. 


\section{Distribution}

1 MS-0755 Daniel Horschel, 6612

10 MS-0755 Wayne Einfeld, 6612

1 MS-0755 Dianna Blair, 6612

1 MS-1423 Phillip Hargis Jr., 1128

1 MS-1423 Gerald Hays, 1128

2 MS-0188 Laboratory Directed R\&D Office, 4523

1 MS-0918 Central Tech Files, 8940-2

5 MS-0899 Technical Library, 4414

2 MS-0619 Review and Approval Desk, 12690

For DOE/OSTI 